\title{
A negligência contra crianças na perspectiva de professores da Educação Infantil
}

\section{pública e privada}

\author{
Neglect against children from the perspective of public and private Early Childhood Education
}

teachers

A negligencia contra los niños desde la perspectiva de los maestros de Educación Infantil pública y privada

Recebido: 19/01/2021 | Revisado: 22/01/2021 | Aceito: 25/01/2021 | Publicado: 31/01/2021

Joice Luiza Alves Cândido

ORCID: https://orcid.org/0000-0002-7666-2372 Universidade Federal de Pernambuco, Brasil E-mail: joice_candido@hotmail.com

Daniela Tavares Gontijo

ORCID: https://orcid.org/0000-0002-2117-0143 Universidade Federal de Pernambuco, Brasil E-mail:daniela.gontijo@ufpe.br

Luciane Soares de Lima Wanderley ORCID: https://orcid.org/0000-0003-4598-8959

Universidade Federal de Pernambuco, Brasil

E-mail: luciane.l.wanderley@gmail.com

Maria Natália Santos Calheiros

ORCID: https://orcid.org/0000-0001-5219-7691

Universidade Federal da Paraíba, Brasil E-mail: mnsc.natalia@gmail.com

\begin{abstract}
Resumo
A violência é considerada um grave problema social e de saúde pública, que pode assumir formas físicas, sexuais, psicológicas ou aparecer na forma de negligência. $O$ enfrentamento da negligência contra crianças exige compreender seu significado nos diversos contextos de vida, dentre eles a educação. O objetivo deste trabalho foi compreender os significados da negligência infantil para educadores de escolas públicas e privadas. Foi realizada uma pesquisa qualitativa numa escola pública e três particulares usando entrevista semiestruturada com quatorze professoras. $\mathrm{Na}$ análise de conteúdo os dados foram organizados nas seguintes categorias: 1) concepções de negligência; 2) agressores e localidades; 3) sinais de negligência; causas e 4) consequências e diferenças na negligência de alunos de escolas públicas e privadas. Destaca-se a importância de ações formativas para identificar, prevenir e assistir às vítimas. Neste processo, o profissional de saúde torna-se imprescindível para agir como articulador da rede de proteção em ações intersetoriais através da educação em saúde.
\end{abstract}

Palavras-chave: Negligência; Educação infantil; Pesquisa qualitativa.

\begin{abstract}
Violence is considered a serious social and public health problem, which can take physical, sexual, psychological forms or appear in the form of neglect. Coping with neglect against children requires understanding its meaning in the various life contexts, including education. The objective of this work was to understand the meanings of child neglect for educators of public and private schools. A qualitative research was conducted in a public school and three private individuals using semi-structured interviews with fourteen teachers. In content analysis, data were organized into the following categories: 1) conceptions of negligence; 2) aggressors and localities; 3) signs of negligence; 4) consequences and differences in the neglect of students from public and private schools. The importance of formative actions to identify, prevent and assist victims is highlighted. In this process, the health professional becomes indispensable to act as articulator of the protection network in intersectoral actions through health education.
\end{abstract}

Keywords: Negligence; Early childhood education; Qualitative research.

\section{Resumen}

La violencia se considera un grave problema de salud social y pública, que puede tomar formas físicas, sexuales, psicológicas o aparecer en forma de negligencia. Hacer frente al descuido contra los niños requiere entender su significado en los diversos contextos de la vida, incluida la educación. El objetivo de este trabajo era comprender los significados de la negligencia infantil para los educadores de las escuelas públicas y privadas. Se realizó una investigación cualitativa en una escuela pública y tres particulares utilizando entrevistas semiestructuradas con catorce 
profesores. En el análisis de contenido, los datos se organizaron en las siguientes categorías: 1) concepciones de negligencia; 2) agresores y localidades; 3) signos de negligencia; 4) consecuencias y diferencias en el abandono de los estudiantes de las escuelas públicas y privadas. Se destaca la importancia de las acciones formativas para identificar, prevenir y asistir a las víctimas. En este proceso, el profesional de la salud se vuelve indispensable para actuar como articulador de la red de protección en acciones intersectoriales a través de la educación para la salud.

Palabras clave: Negligencia; Educación en la primera infancia; Investigación cualitativa.

\section{Introdução}

Em todo o mundo, a violência é considerada um grave problema de saúde pública, com possíveis consequências ao longo do ciclo de vida (Franzin, Olandovski, \& Vettorazzi, 2014; Kim; Sang, \& Trickett, 2010; Krug, Dahlberg, Anthony, \& Lozano, 2002).

A violência pode assumir formas físicas, sexuais, psicológicas ou aparecer na forma de negligência. A negligência, o foco deste estudo, está relacionada à omissão dos pais ou responsáveis por oferecer os cuidados básicos necessários ao desenvolvimento global de crianças e adolescentes. Essa situação inclui privação de medicamentos, falta de assistência e educação em saúde, descuido com a higiene, ausência de condições para frequentar a escola, entre outros. O abandono é uma forma extrema de negligência, pois a criança é exposta a maus-tratos, desnutrição e outras situações de risco (Brasil, 2010; Franzin et al., 2014; Hornor, 2014; Krug et al., 2002).

A negligência precisa ser entendida no contexto da realidade vivenciada pela família, pois diferentes fatores podem estar relacionados à omissão do cuidado ou à impossibilidade concreta de realizar essa tarefa.

Nesse sentido, um dos aspectos centrais desta discussão refere-se às famílias em situação de pobreza e exclusão social, que são, portanto, incapazes de oferecer condições mínimas de cuidado aos filhos (Franzin et al., 2014; Souza, Costa, Assis, Musse, Sobrinho, \& Amaral, 2014). A família, sendo a principal fonte de cuidado, compartilha a responsabilidade por esse descaso com o Estado e precisa de apoio das políticas sociais para superar essas situações (Egry, Apostólico, Albuquerque, Gessner \& Fonseca, 2015).

No entanto, nem sempre é fácil identificar a fronteira entre a omissão e a impossibilidade concreta de prestar assistência na realidade cotidiana dos serviços de saúde e educação das crianças. Além disso, embora a negligência seja um dos principais tipos de violência das quais as crianças são vítimas, é a menos conhecida e marcada pela falta de consenso sobre seu conceito. Ademais, é feito menos investimento público para lidar com suas manifestações (Franzin et al., 2014).

No contexto brasileiro, os pesquisadores definiram quatro tipos de negligência contra crianças e adolescentes: negligência relacionada à proteção contra a exposição a riscos que podem prejudicar a integridade e o desenvolvimento; negligência relacionada à saúde, na qual não são oferecidas condições básicas para uma sobrevivência saudável, como higiene, vacinação, nutrição, entre outras; negligência relacionada à inclusão, continuação e acompanhamento da vida escolar e negligência estrutural, ligada a condições fora do controle direto da família, como condições econômicas e sociais mais amplas (Egry et al., 2015; Franzin et al., 2014).

Porém, diferentes tipos de negligência são encontrados, como físico, emocional, ambiental, cognitivo, médico, educacional, além dos tipos mencionados anteriormente (Wark, Kruczek, \& Boley, 2003).

Outro aspecto importante para entender a complexidade que caracteriza a negligência é a identificação de diferentes níveis de vitimização, variando de maneira contínua, desde a proximidade até o nível ideal de atendimento às necessidades de crianças e adolescentes até a completa inadequação desse cuidado, o que pode acontecer em um momento específico ou ao longo do tempo (Mennen, Kim, Sang, \& Trickett, 2010).

Em relação à sua magnitude, nos Estados Unidos, apenas a negligência corresponde a um terço das causas de mortalidade infantil devido à violência (Welch \& Bonner, 2013). Na faixa etária de 0 a 4 anos, as crianças são cinco vezes mais expostas à violência e duas vezes mais ao homicídio quando comparadas às crianças de 5 a 14 anos (Apostólico, Nóbrega, 
Guedes, da Fonseca, \& Egry, 2012; Krug et al., 2002). Em um estudo desenvolvido na França, metade dos casos de homicídios de crianças entre 1991 e 2008 foram relacionados à negligência dos pais (Makhlouf \& Rambaud, 2014).

No Brasil, na assistência prestada no Sistema Único de Saúde (SUS) devido à violência, a negligência ocupa o quarto lugar com 16\% e ocorre predominantemente na faixa etária de 0 a 4 anos, sendo os pais os principais autores, principalmente no primeiro ano de vida (Waiselfisz, 2015). Em estudo realizado em 19.316 casos de abuso e negligência contra crianças e adolescentes em cinco anos em uma metrópole brasileira, os casos de negligência isoladamente ou associados a outras formas de violência corresponderam a $57 \%$ dos eventos. Na maioria desses casos $(55,5 \%)$, mais de um tipo de negligência foi identificada (Franzin et al., 2014).

A negligência pode acarretar consequências nocivas para crianças e adolescentes em diferentes dimensões da vida, incluindo crescimento, cognição, linguagem, comportamento, emocional, desempenho escolar, comportamento social, entre outras (O'Hara, Legano, Homel, Walker-Descartes, Rojas, \& Laraque, 2015; Schilling \& Christian, 2014) Além disso, a negligência está associada ao aumento da mortalidade infantil e à coexistência de outras formas de violência (O'Hara et al., 2015).

Embora a magnitude e o impacto da negligência no curso da vida tenham sido verificados, crianças e adolescentes vítimas desse tipo de violência figuram entre as pessoas que recebem menos apoio dos serviços de proteção quando comparadas às crianças e adolescentes vítimas de outros tipos de violência. (O'Hara et al., 2015; Schilling \& Christian, 2014).

No Brasil, tanto a Constituição Federal como o Estatuto da Criança e do Adolescente se destacam por sua proteção integral a crianças e adolescentes, designando a garantia de direitos fundamentais como cidadania, dignidade, promoção do bemestar, alimentação, moradia e segurança, entre outros (Lei n. 8.069, 1990). O parágrafo 13 do Estatuto da Criança e do Adolescente (CAS) estabelece que os casos suspeitos e confirmados de maus-tratos a crianças devem ser notificados ao sistema de proteção pública. Além disso, o parágrafo 245 discute a obrigação dos profissionais de saúde e educação de relatar casos suspeitos e confirmados de violência (Lei n. 8.069, 1990).

Além disso, em 2001, o Ministério da Saúde institucionalizou a notificação compulsória de maus-tratos contra crianças e adolescentes atendidos no Sistema Único de Saúde (Brasil, 2001). Mais recentemente, foi aprovada a Lei 13.046 / 14, que altera o CAS e obriga qualquer instituição que ofereça algum tipo de serviço a crianças e adolescentes ou que os abrigue, ainda que temporariamente, para contratar profissionais treinados para reconhecer e relatar ao Conselho Tutelar suspeita ou confirmou casos de maus-tratos contra crianças e adolescentes (Brasil, 2014).

Apesar da existência de garantias legais na proteção de crianças e adolescentes no Brasil e no mundo, existe uma distância entre essas garantias e a realidade dos serviços que as crianças assistem, tendo em vista a subnotificação predominante de casos de violência, incluindo negligência. Os motivos para essa situação incluem: insegurança e falta de preparação para identificar e denunciar situações de violência; não sabendo que a comunicação é obrigatória; descrença nos serviços de referência; medo de retaliação pelo acusado (Apostólico, et al., 2012; Martins, 2010; Ramos \& Silva, 2011).

Nesse contexto, a articulação entre diferentes segmentos sociais, como saúde, educação, serviços sociais, justiça, segurança, representa um dos pilares no enfrentamento e prevenção da violência, incluindo a negligência (Brasil, 2005; Egry et al., 2015; Franzin et al., 2014; Mennen et al., 2010).

Para o bem dessas ações de prevenção e enfrentamento, é necessária uma análise de como a negligência e os aspectos relacionados são entendidos da perspectiva dos diferentes interessados envolvidos no cotidiano das crianças. Esse entendimento é essencial para o aprofundamento de questionamentos críticos sobre as situações de vitimização e para a identificação de aspectos que precisam ser aprimorados para que esses atores sirvam como fonte de proteção efetiva para essas crianças.

Tendo em vista os diferentes contextos em que as crianças vivem, para crianças menores de seis anos, focalizadas neste estudo, a escola figura como um lugar privilegiado para a proteção e detecção de situações de violência e a criação de estratégias 
de enfrentamento. Pode funcionar como um ambiente que apoia o desenvolvimento emocional saudável e a inclusão social ativa, sendo a principal instituição de referência para o início da vida social após e como complemento à família (Ramos \& Silva, 2011; Stelko-Pereira \& Williams, 2010).

Considerando especificamente as pesquisas sobre violência, baseadas em diferentes perspectivas, no Brasil, são priorizados estudos voltados para escolas públicas, cujos alunos tendem a ser crianças e adolescentes de níveis socioeconômicos mais baixos (Cocco, Silva, Silva, \& Jahn, 2014; Faleiros, Matias, \& Bazon, 2009). No entanto, a violência, incluindo a negligência, não se limita a um grupo socioeconômico específico, mas é um fenômeno universal que pode assumir diferentes formas (Franzin et al., 2014).

Portanto, este estudo derivou da investigação de como professores em contextos escolares que atendem crianças de diferentes segmentos socioeconômicos entendem e percebem negligência no cotidiano das crianças com quem vivem.

$\mathrm{Na}$ sistematização desta pesquisa, não pretendemos caracterizar a própria negligência em relação às crianças, pois esse aspecto exigiria outro desenho de estudo, mas entender como os professores significam esse fenômeno, a fim de identificar possíveis aspectos que podem ser aprimorados por meio de profissionais. processos de capacitação, com vistas a contribuir com ações intersetoriais, envolvendo principalmente saúde e educação, voltadas à proteção das crianças.

Assim, o objetivo deste estudo foi compreender os significados da negligência contra crianças segundo educadores de infância de escolas públicas e privadas.

\section{Metodologia}

\section{Contexto do Estudo}

A pesquisa foi desenvolvida em escolas públicas e privadas de Recife/PE. De acordo com a Lei no 9.394 (1996), a educação infantil, a primeira etapa do ensino fundamental, visa o desenvolvimento integral da criança até os seis anos de idade, em seus aspectos físicos, psicológicos, intelectuais e sociais, complementando a família e a família. ações da comunidade (Lei $n^{\circ}$ 9.394, 1996).

Em geral, e de acordo com o contexto do estudo, nas instituições públicas de ensino, os alunos são crianças cujas famílias têm menos poder de compra financeiro. As escolas particulares revelam diferentes configurações em termos de estrutura física, atividades oferecidas às crianças e nível socioeconômico. Neste estudo, no entanto, as escolas particulares participantes caracteristicamente atendem crianças de famílias mais ricas.

\section{Design de estudo}

Este estudo adota uma metodologia de abordagem qualitativa (Pereira, Shitsuka, Parreira, \& Shitsuka, 2018), e o tipo de pesquisa caracteriza-se como naturalista baseada em entrevistas aprofundadas (Flick, 2014). O estudo foi desenvolvido em uma escola pública e três escolas particulares. O número de escolas particulares deveu-se ao fato de que, nas três escolas, apenas um pequeno número de educadores infantis aceitou participar do estudo. As escolas estavam localizadas na mesma região, definidas com base em informações públicas que caracterizavam a região como altamente violenta.

\section{Participantes}

Educadores da infância que trabalhavam nas instituições há pelo menos seis meses foram convidados a participar do estudo. Inicialmente, a proposta de pesquisa foi apresentada ao conselho escolar, que intermediou o contato com a equipe de professores.

Participaram do estudo catorze professoras, sete da escola pública, uma da primeira escola particular, três da segunda e três da terceira. Três professores se recusaram a participar da escola pública e nenhum nas escolas particulares. 
$\mathrm{Na}$ escola pública, a idade dos professores variou entre 26 e 61 anos. A maioria era casada. Todos os professores possuíam um diploma de ensino superior e a maioria um diploma de especialização. A maioria dos educadores (quatro) trabalha em duas escolas, sendo ambas instituições públicas em todos os casos. O tempo de experiência variou entre 03 e 28 anos e o tempo de experiência na educação infantil entre 02 e 24 anos.

Nas escolas particulares, a idade dos professores variou entre 28 e 46 anos e a maioria também era casada. A maioria dos professores possuía diploma de ensino superior, enquanto dois concluíram o ensino médio. Todos os educadores trabalham em apenas uma escola. $\mathrm{O}$ tempo de experiência variou entre 05 e 20 anos e o tempo de experiência na educação infantil entre 03 e 20 anos.

Destaca-se que nenhum dos professores fez curso ou programa de capacitação sobre o tema violência nos dois contextos. O tamanho da amostra, caracterizado como intencional, foi baseado na exaustão, pois foram entrevistados todos os educadores presentes nas instituições, aceitos para participar e cumpridos os critérios de inclusão. No entanto, também foi observada a saturação teórica dos dados, observando a repetição dos conteúdos apresentados pelos participantes nos dois contextos.

Os dados foram coletados por meio de entrevistas individuais aprofundadas, entre março e junho de 2014. As entrevistas foram realizadas em uma sala privada para garantir a privacidade e foram baseadas em um roteiro. $O$ roteiro da entrevista considerou, além das características dos participantes, as seguintes questões norteadoras: o que é violência contra crianças? O que é negligência contra crianças? O que você acha da violência contra crianças que estudam em escolas públicas e privadas? Com base nessas questões norteadoras, os entrevistados puderam apresentar livremente suas opiniões sobre o tema em discussão e foram incentivados pelo pesquisador a detalhar suas percepções no decorrer do período de coleta de dados.

\section{Análise qualitativa}

Com a permissão dos participantes, as entrevistas foram gravadas eletronicamente, transcritas na íntegra e submetidas à análise de conteúdo. A análise foi elaborada em três fases. Primeiro, o material foi sujeito a uma leitura exaustiva e abrangente. Na segunda fase, a exploração dos dados, os procedimentos de codificação e categorização foram postos em prática com a ajuda do software Atlas.ti for Windows (versão 7.0). Na terceira fase do processo de análise, foi elaborada uma síntese interpretativa, que articulou os objetivos do estudo, os dados empíricos e o referencial teórico (Gomes, 2011). Além disso, no decorrer do processo de análise, foram construídos diagramas que facilitam a discussão dos dados.

O processo de análise resultou em cinco categorias temáticas: concepções de negligência, autores e locais de ocorrência, sinais de negligência, causas e consequências da negligência e diferenças entre a negligência que afeta crianças de escolas públicas e privadas.

\section{Ética}

Este estudo recebeu aprovação do Comitê de Ética em Pesquisa envolvendo Seres Humanos do Centro de Ciências da Saúde (CCS) da Universidade Federal de Pernambuco (UFPE) (Parecer 1.165.666) e foi baseado nas diretrizes da resolução CNS n' $466 / 2012$.

\section{Resultados}

\section{Conceitos de negligência}

Inicialmente, os entrevistados foram convidados a indicar que tipos de violência eles conheciam. Os professores de ambas as escolas mencionaram violência física, psicológica e sexual, enquanto apenas um participante da escola pública mencionou negligência. 
Quando perguntados especificamente sobre negligência, os educadores conceituaram esse tipo de violência de diferentes maneiras (Figura 1).

Figura 1 - Conceito de negligência contra a criança para educadores de ensino infantil de escolas pública e privada.

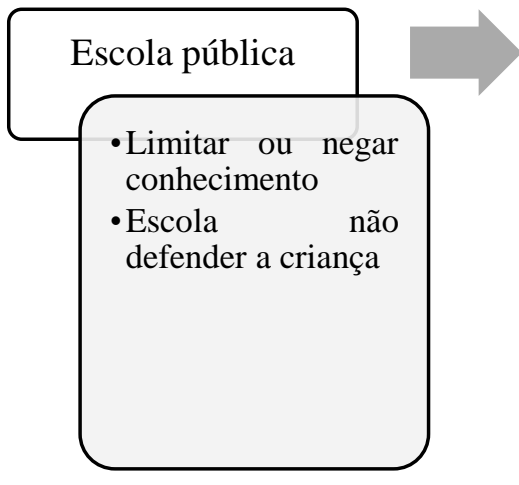

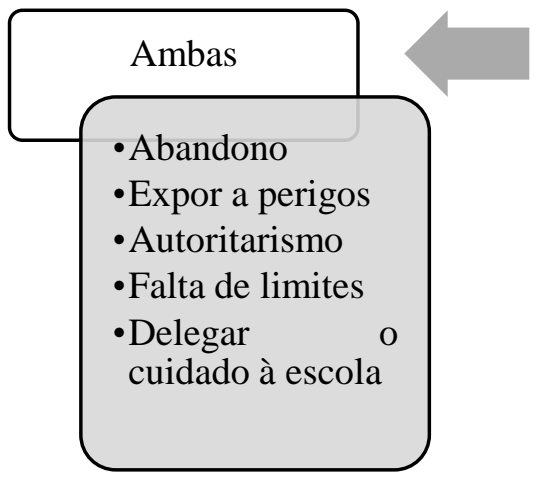

Fonte: Dados das autoras (2014).

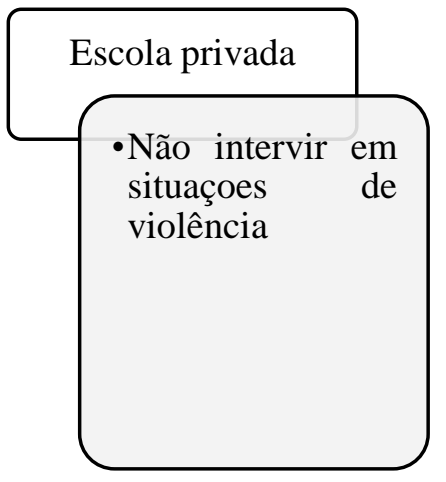

- Não intervir em situaçoes de violência

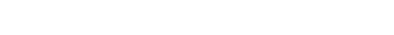

.

É importante atentar-se, na figura, para os diferentes conceitos acerca dos tipos de violência na perspectiva de professores de escolas públicas (à esquerda) e privadas (à direita), bem como para suas intersecções.

Para os participantes de ambas as escolas, negligenciar uma criança envolve abandoná-la completamente ou deixá-la suscetível a situações de perigo.

\section{É quando você não dá mais à criança o que ela precisa. E você negligencia alguns cuidados. (Pub4)}

Negligência é quando você deixa uma criança à mercê de uma situação perigosa. Quando você não se importa, quando não presta atenção, quando não desempenha seu papel de mãe, pai, tio, cuidador ... Professor. (Pri2)

Os entrevistados relatam que negligência é quando não se escuta a criança, quando limites são usados excessivamente ou quando são adotadas práticas educativas autoritárias, em que os cuidadores responsáveis proíbem sem dar maiores explicações. Por outro lado, a criança também é negligenciada quando o cuidador não assume a função de estabelecer limites:

Negligenciar não é ouvir, não definir limites ou fazer muito uso de limites. (Pub1)

Quando ele faz o que quer evitar qualquer confusão, quando a mãe nunca diz não. (Pri5)

Para um educador público, negar ou limitar o acesso ao conhecimento, seja por não frequentar a escola ou por não participar de atividades escolares, é uma forma de negligência. Enquanto isso, os professores de ambas as escolas entendem a delegação de cuidados da criança à escola como negligência:

\section{Negligenciar também é uma agressão de negar às crianças o conhecimento que elas podem ter. (Pub1)}

Negligenciar é deixar que eles façam o que querem ... "O professor resolve, o professor vai e a escola resolve” (Pri1)

Os participantes da escola particular relatam que negligenciar significa perceber que a criança não está bem ou testemunhar uma situação de violência contra a criança e não agir em seu nome:

O ser humano testemunha cenas de agressões: "Ah, não estou envolvido, não é minha família, não é um dos meus alunos, então está tudo bem." Deixe o professor, colega de classe, resolver isso com o aluno; deixe a mãe resolver com o filho. (Pri5) 
Um dos professores da escola pública menciona que a escola pode negligenciar a criança quando não estabelece atividades rotineiras, não oferece ensino adequadamente, se não fornece o material da escola e também se percebe alguma mudança no comportamento da criança ou situação suspeita de violência e não a verifica:

Uma criança também é negligenciada na escola quando o professor não para, para ouvir [...]Então eu estaria negligenciando se visse que o aluno estava faltando tantas aulas e não pedisse para entrar em contato com a família que não 'telefonar para a escola, não fornecer informações [...] Seria negligência na escola se os livros chegassem e eles não os distribuíssem. (Pub1)

\section{Perpetradores e locais de ocorrência}

Quando lhes é pedido que expressem quem são os autores em situações de negligência, os professores nomeiam personagens como: pais, família, professores, amigos, vizinhos, cuidadores ou qualquer pessoa em contato com a criança. Além disso, de acordo com um entrevistado da rede pública, quem testemunha um ato de violência e não faz algo para impedi-lo também é negligente:

Eu acho que todos ao redor ... E quem não pode fazer nada. Ou não por medo. (Pub1)

No que diz respeito aos locais onde ocorre a negligência, os participantes das escolas particulares destacam o contexto familiar e a escola. Além disso, os professores das escolas públicas também apontam as ruas e a igreja:

Está no meio da rua, está em casa, está na igreja. É em todos os lugares que a criança frequenta. (Pub3)

\section{Sinais de negligência}

Os professores também foram questionados sobre os sinais de negligência que eles conhecem ou já testemunharam. A mudança de comportamento é o sinal mais mencionado e os educadores de escolas particulares destacam: tristeza, apatia, timidez e atitudes de isolamento. Por outro lado, as crianças também podem ser agressivas ou adotar atitudes agressivas para tentar atrair a atenção do professor. Para os participantes da escola pública, as mudanças comportamentais mais percebidas são mau humor, apatia e choro.

(...) quando você conhece a criança, vê que ela não está bem, seu comportamento muda, ela não está de bom humor, como costuma estar. (Pub3)

Ele não participa de nada, atrapalha tudo, guarda para si mesmo, tenta atrair sua atenção por algum motivo. (Pri6)

Outro sinal de negligência dos professores nos dois tipos de escola identificados é a falta de cuidado dos pais com as refeições, a saúde, a higiene ou o material escolar:

Maus tratos, às vezes é uma questão de higiene. É um dever de casa bem feito ou não, sujo... Vemos que a mãe... Há alguma condição, mas é negligente, às vezes ela envia a refeição da outra criança na bolsa dele naquele dia ... E é o cuidado da criança que não está lá e você observe isso em suas vestes, em sua ação diária. [...] Ainda hoje, há uma criança com cárie, sofrendo e ela não leva a criança ao dentista. (Pril)

Outro caso de negligência em casa que tive a oportunidade de testemunhar foi um dos meus alunos que cheirava mal todos os dias. Ela realmente fedia e cada vez que tínhamos que lhe dar um banho aqui na escola. Ela veio com a calcinha suja devido a cocô. (Pub5) 


\section{Causas e consequências da negligência}

No que diz respeito à compreensão dos professores sobre as causas da negligência, os participantes do estudo apontaram vários problemas.

O meio social em que os pais foram educados e as situações de pobreza e desemprego podem levar a cuidados negligentes:

Eu também acredito que a pobreza [...] A questão de se vestir, viver ... Cria uma espécie de apatia na mãe, no pai ou em quem quer que seja, e isso faz você não se importar mais, como se estivesse plantando batatas. (Pub7)

Os professores da escola particular apontam que a falta de comprometimento, tempo ou sentimento de responsabilidade da família pelo cuidado com a criança faz com que ela priorize outras coisas, negligenciando a criança. No mesmo sentido, educadores da rede pública mencionam rejeição, falta de cuidados ou um "lar não estruturado", onde as mães estão ausentes de seu papel de cuidadoras para prover sua família:

Partindo da realidade dos pais de meus alunos e da grande maioria dos pais na rede pública, é uma questão de estar ausente ... Trabalhar e não ter ninguém com quem deixar a criança. Então a mãe, ela tem que cuidar da casa. Como ela tem que sair para trabalhar, quem vai passar o tempo com aquela criança? Quem vai lhe dar um banho? Quem vai alimentá-lo? (Pub5)

Às vezes, a falta de tempo devido ao trabalho, por isso e por aquilo e em outros momentos é porque ... Nem todo mundo ... Nasceu para ser mãe, nasceu para ser pai, então ... Acontece que há filhos e pais não pode lidar com as coisas. (Pri2)

Um dos entrevistados da rede privada menciona que o agressor age dessa maneira porque ele já foi vítima. Para um dos professores da rede pública, os atos violentos decorrem do fato de os autores não entenderem que a criança precisa de cuidados e atenção:

Vítimas também, vítimas de negligência, vítimas de ... Desemprego, falta de dinheiro, falta de tudo. Então vai passar de um para o outro, de pai para filho. (Pri4)

Eu acho que a pessoa não percebeu que, como ela, todos nós precisamos dessa atenção, desse cuidado. (Pub1)

As consequências da negligência para os educadores das escolas públicas e privadas são exibidas na Figura 2:

Figura 2 - Consequências da negligência contra a criança para educadores de ensino infantil de escola pública e privadas.
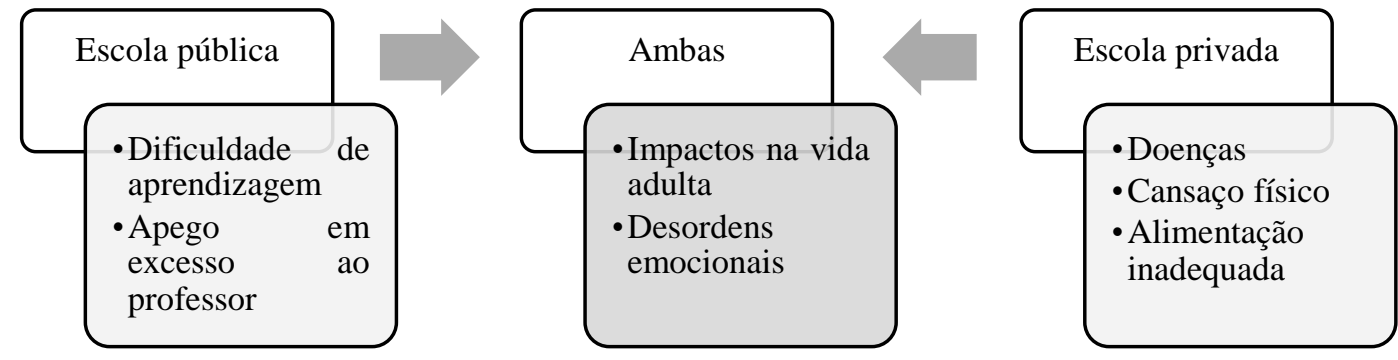

Fonte: Dados das autoras (2014).

É importante observar, na figura, as principais consequências da negligência apontadas por professores de escolas públicas e privadas, evidenciando-se algumas similaridades entre as duas ao centro.

Os educadores apontam que a negligência pode afetar negativamente as crianças a longo prazo: 
Eles acabam sendo adultos violentos porque reproduzem o que experimentaram. Ou um adulto ... Com medo, inseguro e sem afeto, o que é pior, porque ele não recebeu nenhum, então como ele vai ser afetivo com alguém? (Pub7)

Segundo os participantes, as crianças negligenciadas podem apresentar uma ampla gama de distúrbios emocionais. Para os professores da rede privada, as vítimas podem dar sinais de indisposição, indisciplina, irritabilidade, agitação, desânimo e uso da violência. Os professores da rede pública, por sua vez, mencionam falta de autoestima e desorganização, e também sentem que seus cuidadores os desconsideram. Para eles, como resultado de seus distúrbios, as crianças vítimas tenderiam a reproduzir a violência sofrida com outras pessoas ou com elas mesmas:

As crianças chegam cansadas no dia seguinte, não são tão produtivas quanto poderiam ou deveriam, estão sempre indispostas, desanimadas ou irritadas. (Pri5)

É uma troca, eu dou o que recebo. Se eu passei minha vida sendo ignorada, maltratada, negligenciada, então me tornarei esse tipo de pessoa no futuro. Para mim e para outras pessoas. (Pub7)

Os participantes da rede privada também listam problemas de saúde como doenças, fadiga e dieta inadequada:

Às segundas-feiras, chegam com sono, até dormem sentados na cadeira porque vieram de um fim de semana muito cheio, foram dormir mais tarde, crianças que adoecem, porque há todo tipo de dieta. (Pri5)

$\mathrm{Na}$ escola, as vítimas podem apresentar dificuldades de aprendizado e se apegar demais aos professores porque sentem falta dos pais, de acordo com os professores da rede pública:

Eles terão algumas dificuldades de aprendizado. (Pub4)

Saudades do pai ou da mãe. Porque há casos de mães na cadeia, de pais na cadeia. Essa é a principal consequência, a falta [...]percebemos que eles se apegam muito aos professores e contam tudo o que acontece em casa, porque é criado um vínculo de confiança. (Pub5)

\section{Diferenças entre negligência que afetam estudantes de escolas públicas e privadas}

$\mathrm{O}$ aspecto final discutido com os participantes do estudo relacionou-se com o modo como percebem as possíveis diferenças nas situações de vitimização entre crianças de escolas públicas e privadas. Destaca-se que, em suas respostas, os professores apresentaram aspectos gerais da violência e aspectos específicos da negligência.

Alguns professores mencionam que não há ou há uma diferença muito pequena nos dois contextos:

Não há diferença. Há bullying nas duas escolas, há professores e autores negligentes nas duas escolas, há pais cometendo violência nas duas escolas e muitas pessoas boas nos dois tipos de escola. (Pub1)

Mas acho que, a taxa, é ... O mesmo, nos dois. Eu acho que. [...] Talvez o público seja um pouco maior, mas não vejo isso como uma figura flagrante não. (Pri7)

No entanto, alguns entrevistados mencionam uma grande diferença. Alguns participantes indicam que os alunos das escolas públicas são vítimas com mais frequência devido a um nível social mais baixo:

O público, é mais violento, certo? Tipo, risco de violência, você percebe isso entre os alunos, certo? É claro que a violência é muito maior, a taxa de violência nas escolas públicas é terrível. Professores como, desconsiderados, vemos aqueles casos em que um aluno agride um professor, certo? E professores agredindo estudantes também. (Pri3)

As realidades são muito diferentes. Mas a violência acontece em ambos, certo? Mas a herança cultural é muito diferente. (Pri5) 
Talvez seja mais comum encontrar violência nas escolas públicas por causa da situação social dessa criança, entende? Deixe-me fazer uma comparação: a criança que estuda aqui, o nível dela não é o mesmo que a criança que estuda na escola X, onde John, filho do governador, entende? Então, quem estuda os filhos dos professores da faculdade, e aqui os limpadores, os cozinheiros, os auxiliares de manutenção dos filhos. (Pub5)

Segundo os participantes, os alunos das escolas públicas também sofrem mais com a violência por viverem em um contexto violento, vivenciando situações violentas na comunidade, além de aprenderem coisas inapropriadas para a idade:

Isso não significa que as famílias pobres serão violentas, não é isso, mas o meio, a comunidade, entende? Eu tenho estudantes que vivem em um ambiente tão violento que viram o pai sendo assassinado diante de seus olhos [...] então é um meio muito violento, onde circulam muitas drogas. (Pub5)

Então, no meio em que a criança da rede privada mora, isso é uma coisa; o meio em que a criança da rede pública mora é outra coisa, entende? Tem bastante, é ... Muita palavrões, muita música, música vulgar, entende? Então, a sexualidade recebe muita atenção, eles vêem coisas que não têm idade suficiente para ver. (Pub6)

Para os participantes, o nível de educação dos pais também influencia os casos de violência nas escolas públicas e privadas. Nesse sentido, um professor de escola pública menciona que o nível geral de ensino superior dos pais de crianças em idade escolar os faz preparar melhor seus filhos. Um entrevistado da rede privada menciona que o nível de escolaridade geralmente mais baixo dos pais de alunos de escolas públicas pode fazer com que esses pais não prestem atenção em seus filhos:

A educação abre muitos caminhos, filosóficos, para que pensemos antes de agir. [...] coisas que, na escola particular, quando o pai paga 700, 1000 reais hoje por uma, uma mensalidade que é a média que a gente vê hoje, né? Na cidade, então você vê que é um pai que ganha bastante dinheiro, por quê? Porque ele se formou em alguma coisa ou a mãe se formou ou há algum tipo de educação na família, entende? Isso o faz preparar melhor o filho? (Pub6)

A diferença é que, na escola pública, os pais ... Na maioria dos casos, eles não receberam instrução, não prestam atenção, são ... Pessoas sem educação, então agem dessa maneira. (Pri2)

Um participante da rede pública menciona que os alunos de escolas particulares têm mais oportunidades do que os alunos de escolas públicas. Pelo contrário, uma educadora da rede privada menciona que os pais de alunos de escolas particulares tendem a distrair seus filhos com tablets e videogames, em vez de prestar atenção à criança, algo que ela chamou de violência tecnológica:

Acho que as crianças da escola particular têm muito mais oportunidades. (Pub5)

Essa liberdade com a televisão, o vídeo, a Internet, o tablet, os jogos, tudo isso: "Deixe ele, ele está calmo. Então deixe ele lá para que eu possa fazer meu trabalho, para que eu possa fazer minhas coisas. " [...] É uma forma de violência, mascarada, né? Violência tecnológica. (Pril)

Portanto, os professores indicam que os pais de alunos nas redes pública e privada negligenciam seus filhos. De acordo com um professor de escola pública, embora os pais da escola particular deleguem o filho para os outros porque priorizam a ascensão social, os pais das escolas públicas podem negligenciar seus filhos, mesmo quando assumem a função de seus cuidadores:

Não mais colocando a criança em primeiro lugar a colocar seus próprios interesses. $O$ trabalho dos pais que muitos têm, certo? A ascensão na vida profissional e também na vida, é ... Educacional. Então os pais podem ter outros objetivos e que fazem com que essa criança gaste muito tempo sozinha, certo? Nas mãos de outras pessoas. Talvez esteja intimamente ligado a isso e, na escola pública, não vemos tanto, certo? Mas também notamos, certo? E mesmo quando as mães ficam em casa com os filhos, são negligenciadas. (Pub4) 
Os educadores de escolas particulares mencionam que os pais de alunos de escolas particulares delegam os cuidados com seus filhos a outras pessoas, incluindo babás e empregadas domésticas:

Mas, pelo contrário, pais em melhores condições financeiras, que também trabalham mais o dia todo e que precisam deixar seus filhos nas mãos de uma babá ou de outros profissionais, acabam se eliminando. A babá já passou o dia todo com você, a babá já corrigiu o que precisava ser corrigido, então eles acabam delegando funções das quais não participam, certo? (Pri5)

Os professores da rede pública e privada mencionam que as escolas públicas e privadas podem não receber apoio dos pais, pois delegam a função de educar a criança na escola:

Há pais negligentes "porque se eu estou pagando, é a escola que precisa ensinar", há pais negligentes na escola pública: "ah, o professor é pago para ensinar" e muitas vezes precisamos ensinar o básico da família educação para a vida das crianças. (Pub1)

\section{Discussão}

A negligência é uma forma de violência presente no cotidiano de milhares de crianças e pode acarretar graves consequências para o seu desenvolvimento em diferentes dimensões (O'Hara et al., 2015; Schilling \& Christian, 2014; Wark, Kruczek, \& Boley, 2003).

Nesse sentido, é importante implementar medidas de proteção, postas em prática de acordo com cada caso, o mais cedo possível. Essas medidas de proteção só podem ser aplicadas quando as situações de negligência são identificadas nos diferentes contextos da vida das crianças.

Considerando a família como principal lócus de negligência em relação às crianças, principalmente em idades mais jovens, destaca-se a importância da escola na identificação dessas situações e na ativação dos diferentes atores que podem servir como rede de proteção.

$\mathrm{Na}$ escola, o professor é a pessoa que mais se aproxima da criança e, em suas atividades diárias, pode reconhecer situações de negligência, desde que não apenas estejam familiarizados com os sinais de violência que precisam ser identificados, mas também cientes de seu papel como protetores de crianças vítimas.

Assim, este estudo suscita importantes reflexões sobre como os professores significam negligência contra crianças em escolas públicas e privadas. Essas reflexões oferecem apoio que precisa ser levado em consideração no planejamento de ações intersetoriais, entre educação e saúde, que podem fortalecer a rede de proteção das crianças.

Como mencionado anteriormente, no Brasil e em diferentes países, relatar casos de violência, incluindo negligência, é uma obrigação legal para profissionais da educação (entre outros). Não obstante, colocar em prática esse relatório envolve o processo de significação de negligência pelas partes interessadas a ele confrontadas.

Nesse sentido, esses dados do estudo apontam inicialmente a dificuldade de identificar espontaneamente a negligência como forma de violência, em combinação com a existência de diferentes conceitos desse fenômeno, segundo os professores. A falta de identificação espontânea de negligência quando os professores foram questionados sobre os tipos de violência com os quais estavam familiarizados pode estar relacionada à dificuldade de conceituá-la em um contexto mais amplo de "negligência" em relação à negligência contra crianças (Franzin et al., 2014).

Nesse contexto, outros fatores contribuem para a menor visibilidade da negligência quando comparados a outros tipos de violência. De acordo com Franzin et al. (2014), os motivos incluem menor intervenção social em situações de negligência, caracterizada como uma atitude de omissão no cuidado, considerada menos grave quando comparada às ações diretas contra a criança (como no caso de violência física ou sexual). Outro fator a ser considerado é o fato de que a negligência é um tipo de 
violência na qual o agressor pode camuflá-la de diversas formas, confundindo a vítima, o que pode - em alguns contextos - levar à sua naturalização (Silva \& Silva, 2018).

Além disso, aponta-se que esse cuidado e, consequentemente, a análise de sua quantidade e qualidade, estão inseridos em expectativas culturais, que podem variar entre grupos sociais e dificultam a identificação do que é considerado negligente ou não. Além disso, a correlação frequente entre pobreza e negligência (discutida mais adiante neste estudo) também é característica desse contexto de invisibilidade.

Essa complexidade também se forma nos diferentes conceitos que os participantes do estudo apresentam de negligência contra crianças, refletindo a natureza multifacetada da negligência (Brasil, 2010; Krug et al., 2002; Hornor, 2014; Souza et al., 2014). Ao se analisar os conceitos consensuais entre educadores de escolas públicas e privadas, observa-se que, em seus discursos, os participantes valorizaram a compreensão da negligência semelhante à proposta de Franzin et al. (2014), que identifica situações de abandono e exposição a perigos.

No entanto, destaca-se que, neste estudo, os participantes problematizaram a negligência não apenas como "ausência" ou oferta reduzida de assistência, mas também a caracterizaram com base no tipo de relacionamento que os pais estabelecem com a criança. Nesse sentido, identificou-se que a negligência também se caracteriza em relações autoritárias ou marcadas por permissividade excessiva.

Essas percepções revelam a importância de orquestrar os professores para identificar e abordar os diferentes tipos de estilos parentais, a fim de servir como possíveis mediadores na construção de relacionamentos mais protetores no contexto familiar.

Essa orquestração é importante não apenas para identificar as situações de negligência, mas também para outras formas de vitimização, considerando que, na maioria dos casos, as atitudes de negligência em relação às crianças fazem parte de um padrão mais amplo de maus-tratos.

Considerar também o conceito de negligência, no discurso dos professores em ambos os contextos, mostrou claramente a tensão existente nessas situações entre a escola e a família, expressa em formas de negligência relacionada à educação, conforme Franzin et al. (2014). O discurso dos professores apresentou cenas de delegação à escola da responsabilidade pelo cuidado, que eles acreditam que deveriam ser oferecidos pela família das crianças.

Embora essa situação tenha sido destacada nos diferentes antecedentes do estudo, ela precisa ser analisada com mais profundidade, dentro do contexto. Essa análise é justificada pela complexidade, não apenas dos motivos que podem levar a essa delegação de responsabilidades da família para a escola, devido a diferentes questões baseadas no contexto da vida real (inclusão no mundo do trabalho, padrões de interação com crianças, situações de vulnerabilidade social etc.) e também pela importância de os sujeitos que constroem a vida institucional cotidiana refletir sobre o papel das escolas na sociedade contemporânea.

Conforme indicado na literatura, e de acordo com os dados do estudo, a negligência é um fenômeno heterogêneo, difícil de conceituar e requer abordagens mais complexas para o enfrentamento. Aspectos como gravidade, frequência e duração da vitimização são fundamentais para identificar o fenômeno e combater a subnotificação que caracteriza o fenômeno do estudo (Egry et al., 2015; Waiselfisz, 2015).

Considerando a escola como o cenário da vida cotidiana das crianças, os professores são fundamentais para identificar e avaliar essa situação de maneira mais eficaz e dinâmica, desde que sejam sensibilizados, treinados e apoiados por toda a rede de proteção para desempenhar essa função.

Quanto à identificação dos principais agressores das crianças em situações de negligência, em consonância com os diferentes estudos, destacaram-se os familiares mais próximos, responsáveis pelo cuidado direto diário (Apostólico et al. 2012; Egry et al., 2015; Rocha \& Moraes, 2011). 
Os entrevistados identificaram vários sinais de negligência. O sinal mais destacado é a mudança de comportamento, que novamente aponta a importância dos educadores de infância na identificação e prevenção precoces das consequências da violência. Quando estão em contato diário com seus alunos, eles podem perceber facilmente mudanças em seu comportamento, humor e outras atitudes (Lei n. 8.069, 1990).

A falta de cuidado dos pais com a higiene, o material escolar e a escola é mais visível, porque as crianças apresentam sinais claros, como mau cheiro, sujeira, doença ou dever de casa que não foram feitos. Os professores da rede pública observaram esses sinais com mais frequência e, nesse sentido, um estudo aponta que os professores associam esse tipo de violência à falta de condições socioeconômicas e relatam que as crianças da escola pública estão sempre sujas, com roupas e alimentos inadequados (Faleiros, Matias, \& Bazon, 2009).

Além desta identificação, é necessário também valorizar e estimular política públicas que incentivam a participação das escolas no enfrentamento a todo tipo de violência, destacando o papel primordial destas intuições neste processo (Brino \& Souza, 2016).

Neste estudo e na pesquisa mencionada, destaca-se uma visão preconceituosa sobre os alunos de escolas públicas, onde a pobreza está diretamente associada à sujeira. Essas afirmações revelam estigmatização na sociedade, que precisa ser enfrentada, na qual pessoas com condições financeiras mais reduzidas não apresentam cuidados de higiene ou dieta para si e para as pessoas dependendo de seus cuidados.

Os participantes apontaram diferentes causas para a negligência, contra caracterizadas como um fenômeno complexo e multifacetado. Não há um fator único que explique como a violência acontece, pois resulta da interação de fatores individuais e relações sociais, culturais e ambientais (Krug et al., 2002).

Especificamente na relação estabelecida entre pobreza e negligência, mencionada com frequência pelos entrevistados, é importante enfatizar que a negligência ocorre quando existe uma situação de privação, embora os cuidadores responsáveis pela criança tenham meios de prover as situações negadas e devem, portanto, não se confunda com situações de falta econômica (Brasil, 2010; Krug et al., 2002; Souza et al., 2014).

No entanto, alguns autores discutem a existência de negligência estrutural, na qual estão vinculadas as limitações no atendimento a aspectos sociais e econômicos mais amplos, levando a dificuldades em responsabilizar a família pela vitimização, devido a erros no apoio estatal (Franzin et al., 2014; Hornor, 2014).

Além disso, outro problema na associação entre negligência e classe econômica / social é que a violência é mais exposta em contextos sociais mais pobres, o que pode levar a uma falsa interpretação de que a violência é maior, enquanto contextos economicamente mais ricos geralmente têm recursos para tratar a violência secretamente (Faleiros \& Bazon, 2008). Embora a falta social e econômica seja reconhecida como fator para a ocorrência de violência, ela não deve ser reconhecida como fator determinante, pois a violência ocorre em todos os lugares, independentemente do grupo social.

Outro aspecto que requer reflexão é uma possível associação entre baixo nível socioeconômico, baixo nível educacional e negligência. Assim, os pais podem apresentar comportamentos negligentes em relação aos filhos em termos de higiene ou alimentação devido à falta de instrução e não necessariamente devido a problemas financeiros.

Uma educadora da rede pública, mãe e profissional, menciona o fato de a mãe ter que trabalhar e estar ausente dos cuidados com a criança como causa de negligência.

Em um estudo de Egry et al. (2015), foi apontado que, em 11.811 relatos de negligência contra crianças, a mãe foi apontada como a principal responsável por essa situação em quase 70\% dos casos. Esse percentual é ainda maior quando se considera crianças menores de três anos. No entanto, os autores chamam atenção para a importância de entender a participação das mulheres como perpetradoras no contexto dos conceitos de gênero predominantes na sociedade brasileira. Historicamente, no Brasil, o cuidado direto aos filhos é delegado à mãe, mesmo em contextos nos quais ela é a provedora financeira da família, 
pois os homens dificilmente participam dessas práticas envolvendo os filhos. Essa responsabilidade pelo cuidado dos filhos é inversamente proporcional à idade das crianças, ou seja, quanto mais jovem a criança, maior a participação das mães nos cuidados, em detrimento da participação paterna.

A responsabilidade "cultural" das mulheres pelos cuidados com as crianças (principalmente entre as crianças mais novas, o foco deste estudo) esteve presente durante todo o processo de pesquisa, uma vez que poucas entrevistas continham alegações de que relacionavam os cuidados com as crianças (e a falta desses cuidados) com pais ou outras figuras masculinas.

Nesse sentido, como destacou a entrevistada, a inclusão e participação das mulheres no mundo do trabalho pode não ter mudado, pelo menos ideologicamente, a dinâmica socialmente construída de considerar o cuidado doméstico como natural para as mulheres, considerando que, na maioria dos casos, as responsabilidades por isso os cuidados não são compartilhados com os homens (quando presentes no contexto familiar).

Portanto, é importante que a escola e outros equipamentos de apoio social não reproduzam a representação de mulheres / mães como a única responsável pelo cuidado da criança em seus serviços, tentando envolver não apenas o pai, mas também outras pessoas de referência da criança em seus serviços/cuidados dela.

Além das questões de gênero, outros aspectos precisam ser discutidos para responsabilizar as mães por situações de negligência. De acordo com Franzin et al. (2014), vários pesquisadores associaram negligência à falta de / redução da empatia dos pais com os filhos. Essa empatia limitada pode estar relacionada a diferentes aspectos, como idade da mãe, uso de álcool e outras drogas, mas também a história de abuso e negligência da qual a mãe foi vítima na infância. Nesse sentido, observa-se um "ciclo de maus-tratos" entre gerações, à medida que as mães repetem as atitudes abusivas com as quais viviam quando eram crianças.

Nesse contexto, a oferta de serviços que servem como fonte de apoio social é vital para "quebrar" esse ciclo de maustratos entre gerações. De acordo com Egry et al. (2015), o acesso ao apoio social pode contribuir para aprimorar atitudes de empatia e resiliência no processo materno, em relação às crianças vítimas e ações para prevenir as situações de violência.

Nesse sentido, a escola pode intermediar o acesso de mães e outras figuras assistenciais vítimas na infância a serviços de apoio social. Portanto, são necessárias ações educativas para a construção de apoios que permitam aos profissionais não apenas identificar as situações, mas também ativar a rede de proteção.

Os educadores apontaram diferentes consequências da vitimização, como distúrbios emocionais, problemas de saúde e dificuldades de aprendizado. Os autores apontam que crianças negligenciadas podem apresentar hospitalizações recorrentes, lesões repetitivas, desenvolvimento insuficiente e inadequação do nível escolar ou absentismo escolar e falta de atenção (Brasil, 2010; Egry et al., 2015; Wark, Kruczek, \& Boley, 2003). Ser vítima desse tipo de violência na infância está associada a doenças isquêmicas, asma, câncer de pulmão e comportamento sexual de risco na vida adulta (Souza et al., 2014). Vítimas de negligência também podem apresentar sinais de transtorno de estresse pós-traumático (Milot, St-Laurent, Éthier, \& Provost, 2015). Em um estudo envolvendo crianças negligenciadas em idade pré-escolar, surgiram estratégias de interação social inseguras e inadequadas quando comparadas às crianças que não foram maltratadas (Benavente; Justo, \& Veríssimo, 2009).

Um aspecto final deste estudo refere-se às percepções dos entrevistados sobre possíveis diferenças e semelhanças entre as situações de negligência em crianças de escolas públicas e privadas.

Nesse sentido, os entrevistados reconhecem que existe violência nas duas escolas, mas, segundo a maioria dos professores, principalmente nas escolas particulares, os alunos das escolas públicas são mais vítimas. A explicação para essa percepção, segundo os participantes, é o baixo nível de escolaridade e as condições socioeconômicas dos pais desses alunos, além do contexto social em que estão inseridos.

Em seu discurso, observa-se que os professores consideram que os alunos das escolas públicas são de famílias de baixa renda e vivem em comunidades mais pobres. Eles associam a violência à falta de condições financeiras, como discutido 
anteriormente. Há uma ideia generalizada de que as escolas públicas existem em um contexto de falta, enquanto as escolas particulares apresentam a melhor estrutura. No entanto, deve-se levar em consideração que, embora existam escolas públicas servindo como escolas modelo, onde muitos alunos em melhores condições financeiras estão matriculados, há escolas particulares de baixa qualidade funcionando precariamente.

Outro aspecto que também deve ser considerado é que essa narrativa se destacou no discurso de professores de escolas particulares, que não lidam com os alunos que consideram mais vitimizados em sua realidade cotidiana. Isso pode apontar para a negação ou omissão desses educadores da existência de violência na rede privada de ensino, o que pode levar a uma menor subnotificação de casos nessas escolas e consequente dano às crianças.

Coco, Silva, Silva e Jahn (2014) entrevistaram educadores sobre violência doméstica e identificaram que negavam a existência de violência na escola onde lecionavam, devido ao fato de a população atendida ter um melhor nível socioeconômico. Os autores enfatizaram a necessidade de identificar famílias em risco, independentemente da situação financeira, pois essas informações não desempenham papel determinante para a presença de violência nas famílias.

Especificamente em relação à negligência, os entrevistados mencionam que crianças que estudam em escolas públicas e privadas são vítimas, mas de forma diferente. Enquanto as crianças da rede pública são vítimas de negligência física, caracterizada pelo não atendimento às necessidades básicas das crianças em termos de saúde, higiene e alimentação, as crianças da rede privada são vítimas de negligência emocional, quando as necessidades de atenção e carinho são importantes. para o desenvolvimento saudável, são negados. Nesses casos, de acordo com os professores, embora os pais atendam às necessidades físicas de seus filhos, a busca pela ascensão profissional os faz priorizar o trabalho e delegar os cuidados com o filho a outras pessoas e até à escola. Os autores também chamam esse tipo de violência de negligência afetiva ou emocional e mencionam que, nas classes sociais média e alta, a ausência dos pais em termos de diálogo, afeto e atenção às crianças é mais frequente, com consequências para o comportamento das crianças (Russo, Dantas, Nogueira, \& Trindade, 2012).

A negligência emocional está relacionada ao fracasso em se relacionar com, "conectar-se", ao vínculo emocional com a criança nas práticas parentais (Wark; Kruczek, \& Boley, 2003). Esse vínculo não pode ser entendido como algo fechado, mas como um continuum cujo extremo negativo resulta em comportamentos negativos. No entanto, é importante desenvolver pesquisas para entender como essas situações de negligência se formam em diferentes dinâmicas familiares, o que pode acontecer em diferentes contextos econômicos e sociais. Além disso, destaca-se, nesse contexto, o potencial das ações de proteção intersetorial para construir, junto às famílias, dinâmicas familiares que proporcionem cuidados efetivos e necessários às crianças (Egry et al., 2015; Wark, Kruczek, \& Boley, 2003).

\section{Limitações do Estudo}

Uma limitação deste estudo foi o fato de os participantes não trabalharem nos dois contextos analisados, ou seja, em escolas públicas e privadas. A experiência profissional em ambos os contextos poderia contribuir para reflexões mais profundas sobre a ocorrência de negligência.

\section{Considerações Finais}

Embora os resultados deste estudo não possam ser generalizados, a existência de negligência em diferentes contextos socioeconômicos com diferentes "aparelhos" revela a importância de reflexões mais aprofundadas, sobre as associações estigmatizantes que tendem a ser feitas entre pobreza e violência. Essa estigmatização pode assumir a forma de um fator que limita a proteção das crianças de grupos socioeconômicos mais ricos, pois o problema não é reconhecido. 
O fenômeno da negligência na infância deve ser estudado em seus diferentes ramos e associado a outros aspectos, como questões econômicas e de gênero, por exemplo. Essa análise mais profunda pode contribuir para a articulação de políticas e ações mais adequadas às particularidades dos contextos reais da vida.

Embora as crianças na educação infantil apresentem maior vulnerabilidade, quando os relatos dos entrevistados são confrontados com a literatura, pouca diferença foi observada nos estudos sobre violência contra crianças mais velhas. Em consonância com essa percepção, menos estudos foram observados focados nessa faixa etária, exigindo novas pesquisas para aprofundar a compreensão desse fenômeno e como ele ocorre, considerando os lugares sociais da criança e os diferentes estilos de prática dos pais.

Considerando a dificuldade de reconhecer a negligência como forma de violência, apesar de sua presença no cotidiano da criança em ambos os contextos, são importantes as ações educativas, que contribuem para a construção do conhecimento não apenas para a identificação, mas principalmente para o estabelecimento de medidas preventivas e preventivas. medidas de assistência às vítimas.

Isso explica a importância de trabalhar em rede, na qual a responsabilidade de relatar muda do profissional para a instituição, que deve se envolver no monitoramento da criança e da família, no encaminhamento e nas intervenções diretas (O'Hara et al., 2015).

Essas medidas incluem a construção de ações intersetoriais, nas quais os profissionais de saúde podem desempenhar um papel destacado. Entre as possíveis contribuições desses profissionais, a educação em saúde é uma ferramenta potencialmente eficaz.

A educação em saúde, baseada principalmente em métodos participativos, é uma estratégia que visa capacitar os diferentes atores envolvidos no enfrentamento desse problema. Com base no diálogo, na conscientização crítica e na responsabilização de todos pela proteção das crianças, deve promover o engajamento não apenas dos professores e outros profissionais da escola, mas principalmente dos familiares e cuidadores.

Além disso, os profissionais de saúde podem atuar como articuladores da rede de proteção, principalmente para crianças que já são vítimas, para garantir que recebam atendimento em todas as dimensões necessárias, incluindo atendimento na saúde, serviço social e rede legal.

Sugerimos, para pesquisas futuras, estudos com profissionais que trabalhem simultaneamente em ambos os contextos analisados (escolas pública e privada) para que seja possível aprofundar as questões aqui discutidas e ampliar o debate sobre a negligência contra crianças.

\section{Referências}

Apostólico, M. R., Nóbrega, C. R., Guedes, R. N., da Fonseca, R. M. G. S., \& Egry, E. Y. (2012). Características da violência contra a criança em uma capital brasileira. Revista Latino-Americana de Enfermagem, 20(2), 266-273. https://doi.org/10.1590/S0104-11692012000200008.

Benavente, R., Justo, J., \& Veríssimo, M. (2009). Os efeitos dos maus-tratos e da negligência sobre as representações da vinculação em crianças de idade préescolar. Análise Psicológica, 27(1), 21-31.

Lei n. 8.069/90. Dispõe sobre o Estatuto da Criança e do Adolescente (1990): $M E C$.

Lei no 9.394/96. Estabelece as Diretrizes e Bases da Educação Nacional (1996). Centro de documentação e Informação-Coordenação de Publicações. Câmara Federal dos Deputados: Brasília-DF.

Política Nacional de Atenção Integral à Saúde da Criança: Secretaria de Atenção à Saúde.

Cocco, M., Silva, E. B. D., Silva, C. M. D., \& Jahn, A. D. C. (2010). Violência contra crianças: dimensões apreendidas nas falas de professoras de educação infantil e a articulação com o setor saúde. Revista Mineira de Enfermagem, 14(4), 539-547.

Egry, E. Y., Apostólico, M. R., Albuquerque, L. M., Gessner, R., \& Fonseca, R. M. G. S.da. (2015). Compreendendo a negligência infantil na perspectiva de gênero: estudo em um município brasileiro. Revista da Escola de Enfermagem da USP, 49(4), 0556-0563. https://doi.org/10.1590/S0080-623420150000400004 
Faleiros, J. M., Matias, A. D. S. A., \& Bazon, M. R. (2009). Violência contra crianças na cidade de Ribeirão Preto, São Paulo, Brasil: a prevalência dos maustratos calculada com base em informações do setor educacional. Cadernos de Saúde Pública,25, 337-348. http://dx. doi.org/10.1590/S0102311 X2009000200012.

Flick, U. (2014). Introdução à pesquisa qualitativa. Artmed.

Franzin, L. C. da S., Olandovski, M., Vettorazzi, M. L.T., Ozetto, G., Werneck, R. I., Moysés, S. J., Kusma, S. Z., \& Moysés, S. T. (2014). Child and adolescent abuse and neglect in the city of Curitiba, Brazil. Child Abuse \& Neglect, 38(10), 1706-1714. https://doi.org/10.1016/j.chiabu.2014.02.003

Gomes, R. (2011). Análise e interpretação de dados de pesquisa qualitativa. In: Minayo, M. C. S. (ed.), Pesquisa social: teoria, método e criatividade (pp 79108). Vozes.

Hornor, G (2014). Negligência infantil: Avaliação e intervenção. Journal of Pediatric Health Care, 28(2), $186-192$.

Krug, E. G., Dahlberg, L., Anthony, B. Z., \& Lozano, R. (2002). Relatório mundial sobre violência e saúde. Genebra: Organização Mundial da Saúde.

Makhlouf, F., \& Rambaud, C. (2014). Child homicide and neglect in France: 1991-2008. Child abuse \& neglect, 38(1), 37-41. https://doi.org/10.1016/j.chiabu.2013.08.016

Mennen, F. E., Kim, K., Sang, J., \& Trickett, P. K. (2010). Child neglect: Definition and identification of youth's experiences in official reports of maltreatment. Child abuse \& neglect, 34(9), 647-658. https://doi.org/10.1016/j.chiabu.2010.02.007

Milot, T., St-Laurent, D., Ethier, L. S., \& Provost, M. A. (2010). Trauma-related symptoms in neglected preschoolers and affective quality of mother-child communication. Child Maltreatment, 15(4), 293-304. https://doi.org/10.1177/1077559510379153

O’Hara, M., Legano, L., Homel, P., Walker-Descartes, I., Rojas, M., \& Laraque, D. (2015). Children neglected: Where cumulative risk theory fails. Child abuse \& neglect, 45, 1-8. https://doi.org/10.1016/j.chiabu.2015.03.007

Pereira, A. S., Shitsuka, D. M., Parreira, F. J., \& Shitsuka, R. (2018). Metodologia da pesquisa científica [e-book]. Santa Maria. Ed (pp. 3-9). UAB/NTE/UFSM.

Ramos, M. L. C. O., \& Silva, A. L. D. (2011). Estudo sobre a violência doméstica contra a criança em unidades básicas de saúde do município de São PauloBrasil. Saúde e Sociedade, 20, 136-146. http://dx.doi.org/10.1590/S0104-12902011000100016

Russo, G., Dantas, J., Nogueira, J., \& Trindade, H (2014). Da omissão denunciada: negligência intrafamiliar contra crianças e adolescentes no Creas/MossoróRN/The omission denouced: intrafamiliy negligence against children and adolescents in the Creas/Mossoró-RN. SER Social Brasília, 16(34), 65-90.

Schilling, S., \& Christian, C. W. (2014). Child physical abuse and neglect. Child and Adolescent Psychiatric Clinics, 23(2), 309-319. https://doi.org/10.1016/j.chc.2014.01.001.

Silva, M. D., \& Silva, A. G. D. (2018). Professores e Alunos: o engendramento da violência da escola. Educação \& Realidade, 43(2), 471-494. https://doi.org/10.1590/2175-623664089.

Souza, C. D. S., Costa, M. C. O., Assis, S. G. D., Musse, J. D. O., Sobrinho, C. N., \& Amaral, M. T. R. (2014). Sistema de Vigilância de Violências e Acidentes/VIVA e a notificação da violência infanto-juvenil, no Sistema Único de Saúde/SUS de Feira de Santana-Bahia, Brasil. Ciência \& Saúde Coletiva, 19, 773-784. https://doi.org/10.1590/2175-623664089.

Stelko-Pereira, A. C., \& de Albuquerque Williams, L. C. (2010). Reflexões sobre o conceito de violência escolar e a busca por uma definição abrangente. Temas em psicologia, 18(1), 45-55. https://www.redalyc.org/comocitar.oa?id=513751435005.

Waiselfisz, J. J. (2015). Violência letal contra as crianças e adolescentes do Brasil.: Flacso.

Wark, M. J., Kruczek, T., \& Boley, A. (2003). Emotional neglect and family structure: impact on student functioning. Child abuse \& neglect, 27(9), 1033-1043. https://doi.org/10.1016/S0145-2134(03)00162-5.

Welch, G. L., \& Bonner, B. L. (2013). Fatal child neglect: Characteristics, causation, and strategies for prevention. Child Abuse \& Neglect, 37(10), 745-752. https://doi.org/10.1016/j.chiabu.2013.05.008. 